\title{
Clinical and radiological predictors of outcome in cerebral venous sinus thrombosis: An observational study
}

\author{
Amandeep Singh, Rahul Jain, Dinesh Chouksey, Ajoy Sodani \\ Department of Neurology, Sri Aurobindo Medical College and Post Graduate Institute, Indore, India
}

\begin{abstract}
Background. Objective. There have been varying clinical and radiological presentations in cerebral venous thrombosis (CVT) and there is ambiguity about predictors for the clinical outcome, so we planned a prospective observational study to predict clinical and radiological parameters of outcome in CVT patients.

Material and methods. The study was conducted in the Department of Neurology, of a tertiary care hospital. We studied demographic, clinical, and radiological features of $40 \mathrm{CVST}$ patients and correlated with the clinical outcome as Independent/good or dependant/death/poor at discharge and at one year using mRS score.

Results. The study included $n=40$ patients with a mean age of 32.45 years. The mean duration of hospital stay was $7.85 \pm 3.69$ days. Headache was the most prevalent clinical feature in $95 \%$. Superior sagittal sinus with or without inferior sagittal sinus was the most commonly thrombosed in $(n=27,67.5 \%)$ patients. In the study population, $24(60 \%)$ patients had good/independent outcome and $16(40 \%)$ patients had dependant/death/poor outcome at discharge. We found that $84.62 \%$ of patients with parenchymal lesions with mass effect group had dependant/death/poor outcome and none of the patients without parenchymal lesion were dependent/dead and all had independent/good outcome at discharge. Although in the majority (54\%) patients of parenchymal lesion with mass effect, the late outcome (at one year) was good.

Conclusions. Our study concluded that higher GCS score at admission and discharge with radiological features of the absence of parenchymal lesion and parenchymal lesion without mass effect were strong predictors for good/ Independent clinical outcome (early as well late). But presentation as focal neurological deficits, headache with lower GCS, presence of parenchymal lesion with mass effect, and unilateral large parenchymal lesions were strong predictors for dependant/death/poor outcome.
\end{abstract}

Keywords: cerebral venous thrombosis, follow-up, MRI, MRV, CVST score, stroke, outcome, risk factors

\begin{abstract}
Abbreviations
mRS - modified Rankin's score

CVT - cerebral venous thrombosis

MRV - MRI venography

PPV - positive predictive value

NPV - negative predictive value
\end{abstract}

\section{INTRODUCTION}

Cerebral venous thrombosis (CVT) is a rare but important cause of stroke-like illness and accounts for less than $1 \%$ of all strokes with a varying range of clinical presentations, predisposing factors, radiological features and outcomes [1]. The cerebral venous system can be divided into a superficial and a deep system. The superior sagittal sinus is the most common site of occlusion, followed by transverse, sigmoid, and cavernous sinuses in the superficial venous system. The deep system involves the internal cerebral veins, sometimes extending into great vein of Galen and the straight sinus [2]. Depending on the site, size, duration, and rapidity of thrombus development, it can present as headache, seizures, focal neurological deficits, or unexplained loss of consciousness [3]. It is 
important to be aware of the varied clinical presentation and course of CVT, as most of these patients may have an excellent outcome if treated early and appropriately [4,5].

With the widespread availability of magnetic resonance imaging (MRI), many more cases of CVST are being diagnosed now than before. Radiological features like the involvement of any particular sinus, the number of sinuses involved, and the presence of parenchymal lesions as a predictor of outcome have been studied before in only few studies $[1,6,7]$.

The presentation of CVT is not stereotyped and there has been ambiguity about clinical and radiological predictors of poor outcome. As some of the studies have found the importance of low GCS at presentation, presence of focal neurological deficits, and deep venous system, as the predictors of poor outcome [8] and few studies have focused on radiological factors like number of sinuses involved, site of venous infarct and presence of parenchymal lesions to predict poor outcome. Some recent studies have reported CVST score (radiological score), and parenchymal lesions as independent predictors of clinical outcome while Kalita et al. found death and disability not to be related to this radiological score $[1,7]$.

Therefore we planned to do a prospective observational study to predict clinical and radiological parameters of outcome in CVT patients.

\section{AIMS AND OBJECTIVES}

We aimed to study demographic, clinical, and radiological features of CVT, to correlate clinical and demographic features with radiological characteristics and to find predictors of a good and bad outcome.

\section{MATERIAL AND METHODS}

The study was conducted in the Department of Neurology, of a tertiary care teaching hospital from central India. This was a prospective observational study. The patients were recruited from July 2018 to March 2020. All hospitalized patients, diagnosed to have cerebral venous sinus thrombosis (CVT) and fulfilled the inclusion criteria were enrolled in the study after taking the informed consent. Old treated cases of CVT, patients without
MRI, and non-consenting patients were excluded. Written consent was obtained from all patients. The study has been approved by the research and ethical committee of the institute (IEC No. SAIMS/ IEC/2019/32).

One of the investigators (AS) recorded demographic and clinical details of patients in a structured proforma. Data regarding age, gender, body mass index (BMI), presenting complaints, clinical features, risk factors, laboratory parameters were recorded.

MRI brain and MR venography was done on 1.5 Tesla Siemens. 2-D time of flight (TOF) venography was done in the patients with Voxel image resolution of 254. Radiological characteristics as per the type and number of sinuses involved, and the presence of parenchyma lesions if any were recorded.

Glasgow coma score (GCS) and modified Rankin score (mRS) were recorded at the time of admission and discharge from the hospital. For outcome analysis, all patients were subdivided into two groups. Subjects who were ambulatory and independent in doing their routine activities with $\mathrm{mRS}(0-2)$ at the time of discharge from the hospital were considered to have good outcome/Independent. Subjects who were dependent and needed assistance to perform routine work, required surgery at presentation, and died had mRS (3-6) were considered to have poor outcome/dependent or dead. The outcome of the patients was evaluated at two points of time, first at the time of discharge (early outcome) and later at one year of discharge (through telephonic interview or follow-up visits) and was labeled as the late outcome.

Data were entered in Microsoft excel sheet and statistical analysis was done using statistical software, SPSS version 17.0.spss version trial. Comparison of proportions, t-test, Karl Pearson's coefficient of correlation, logistic regression, univariate and multivariate analysis was done to calculate the level of significance as and when required.

\section{RESULTS}

\section{Demographic profile}

A total of 40 patients $(n=40)$ of CVT participated in the present study who met the inclusion criteria. The age of all subjects was obtained in the 
ranges from 18 to 55 years. Out of total study subjects $(n=40)$, males constituted $60 \%(n=24)$ of the population.

The mean age of all subjects found to be $32.45 \pm 9.25$ (mean $\pm \mathrm{SD}$ ) years. The average age of females $(28.81 \pm 5.32$ years $)$ was found to be smaller as compared to males (34.88 \pm 10.55 years). Average BMI was found to be $23.26 \pm 4.13 \mathrm{~kg} / \mathrm{me}-$ $\operatorname{ter}^{2}$ (Range $16.65-36.74 \mathrm{~kg} / \mathrm{meter}^{2}$ ). Area of residence of patients showed that CVT was more prevalent in patients living in urban areas $(65.0 \%)$ as compared to rural areas (35.0\%).

Average length of the pre-hospitalization period (symptom onset to hospital admission) was $10.275 \pm 12.09$ days (range 1 to 77 days). The mean duration of hospital stay was $7.85 \pm 3.69$ days (range 1 to 22 days) with a median duration of 7 days.

The mean GCS score at admission was $13.70 \pm 2.45$ (range 3 to 15 ), the mean GCS at discharge was $13.95 \pm 3.16$ (range 3 to 15 ).

The mean $\mathrm{mRS}$ score at discharge was found to be $2.58 \pm 1.56$ (range - 1 to 6 ) while the mean mRS at 1year (late outcome) was found to be $1.375 \pm 1.81$ (range -1 to 6 ).

\section{Clinical profile}

Headache ( $\mathrm{n}=38,95.0 \%)$ was the most prevalent clinical feature among the patients with CVT, followed by papilledema $(\mathrm{n}=30,75.0 \%)$, seizures $(\mathrm{n}=19,47.5 \%)$ and altered sensorium in $(\mathrm{n}=15$, $37.5 \%)$ patients. Further, results showed that the focal neurological deficit $(\mathrm{n}=13,32.5 \%)$ was the fifth most prevalent clinical feature followed by visual symptoms $(\mathrm{n}=12,30.0 \%)$ and sensory features $(\mathrm{n}=8,20.0 \%)$ whereas aphasia $(\mathrm{n}=3,7.5 \%)$ found to be the least common clinical feature.

The assessment of risk factors revealed that hyper-homocysteinemia was the most common risk factor in $(\mathrm{n}=22,55.0 \%)$ of the patients with CVT. Out of the total study population $(n=40)$, the acquired risk factors e.g. alcohol $(n=9,22.5 \%)$, pregnancy/postpartum state $(n=7,17.5 \%)$, smoking $(\mathrm{n}=6,15.0 \%)$, oral contraceptive pills $(\mathrm{n}=5$, $12.5 \%)$ and infection $(n=3,7.5 \%)$ were present with above mentioned frequency. The genetic thrombophilia profile was done in 7 patients out of which one patient had antithrombin-3 deficiency and another patient had Protein $\mathrm{C}$ deficiency.

\section{Radiological profile}

Superior sagittal sinus with or without inferior sagittal sinus thrombosis was the most common in ( $\mathrm{n}=27,67.5 \%)$ patients, followed by right transverse sinus $(\mathrm{n}=18,45 \%)$, left transverse sinus thrombosis in $(n=20,50.0 \%)$ patients. Right and left sigmoid sinus thrombosis with or without internal jugular vein was present in $(\mathrm{n}=19,47.5 \%)$ and $(\mathrm{n}=16,40.0 \%)$ patients respectively. Cortical veins thrombosis was seen in $(\mathrm{n}=12,30.0 \%)$, unilateral parenchymal lesions $<30 \mathrm{ml}$ were present in $(\mathrm{n}=11,27.5 \%)$, unilateral parenchymal lesions $>30 \mathrm{ml}$ were present in $(\mathrm{n}=11,27.5 \%)$, bilateral parenchymal lesions $<30 \mathrm{ml}$ were present in $(\mathrm{n}=3,7.5 \%)$, and bilateral parenchymal lesions $>30 \mathrm{ml}$ were not seen in $(\mathrm{n}=0)$ any of our patients.

Out of the total study population $(n=40)$ multiple sinuses involvement was present in $30(75 \%)$ patients while $10(25 \%)$ had single sinus thrombosis.

The most common site of parenchymal lesion was parietal lobe $(\mathrm{n}=13)$, followed by temporal lobe $(n=8)$, frontal lobe $(n=7)$, thalamus $(n=2)$, and occipital lobe $(n=1)$.

In the radiological characteristics there was no parenchymal lesion in $\mathrm{n}=15(37.5 \%)$ patients, parenchymal lesion without mass effect in $\mathrm{n}=12$ (30\%) patients and $n=13(32.5 \%)$ patients had parenchymal lesion with mass effect.

\section{OUTCOME ANALYSIS}

For outcome analysis study population $(\mathrm{n}=40)$ was sub-grouped into two groups (good outcome/ independent with $\mathrm{mRS} \leq 2$ ) and (poor outcome/ dependent or dead with $\mathrm{mRS} \geq 3$ ). Among the total study population, $24(60 \%)$ patients had good/independent outcome and $16(40 \%)$ patients had poor outcome/were dependant or dead at discharge. While it was observed that the late clinical outcome (at one year) was independent/ good in 33 $(82.5 \%)$ patients and $7(17.5 \%)$ patients had poor outcome and were dependant or dead.

On analysis of demographic variables with the outcome, it was found that there was no significant difference in age, gender, and area of residence among two subgroups $(p>0.05)$. However, the type of presentation significantly differed between two subgroups $(p<0.002)$. Patients with focal 

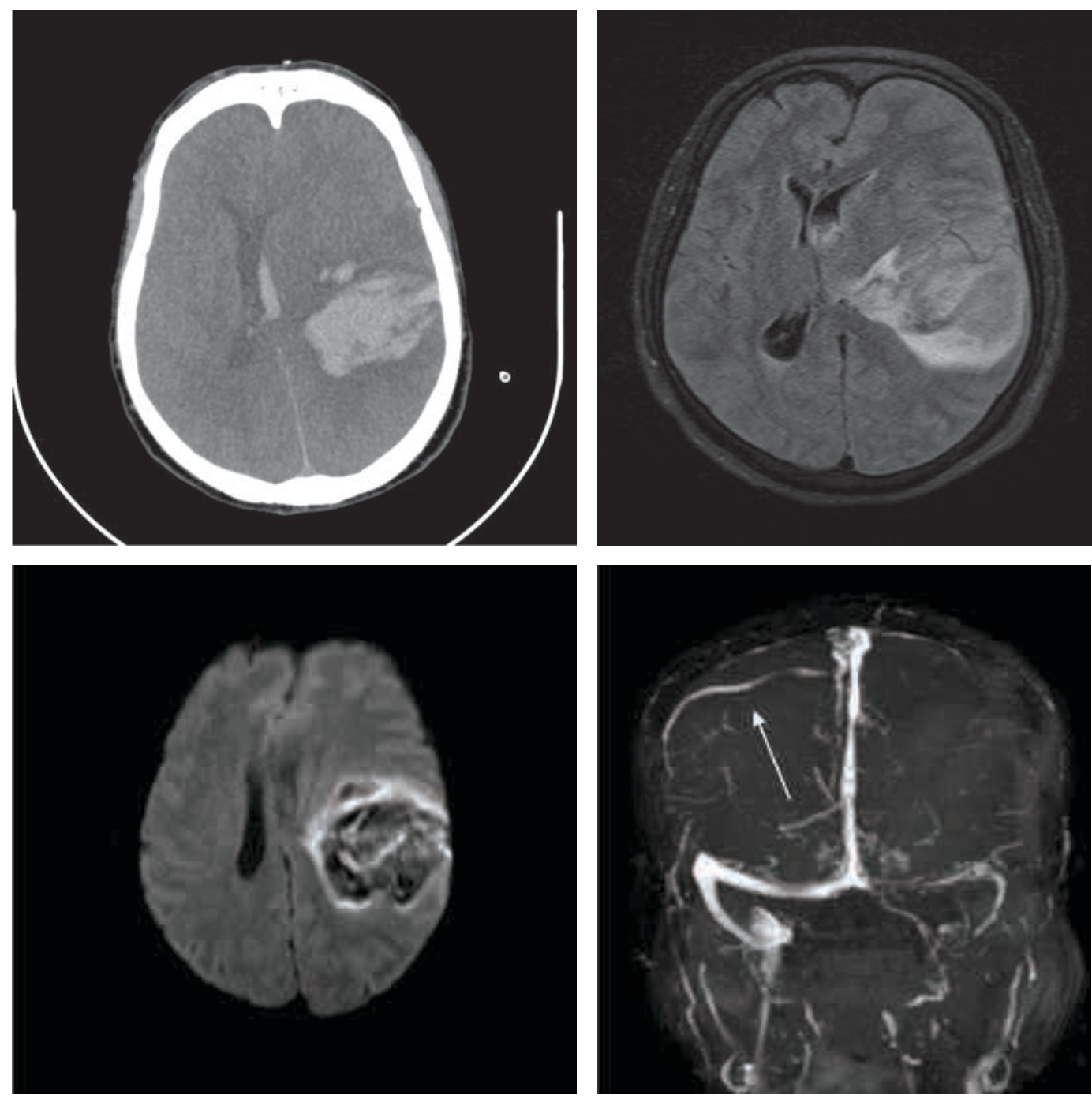

FIGURE $1(a, b, c, d)$. The above CT and MRI Flair and diffusion brain images of one patient with large left parietal venous infarct with mass effect and midline shift and venogram showing left transverse, sigmoid and IJV thrombosis. Vein of Trolard is seen draining on right side of superior sagittal sinus in fig $1(d)$.
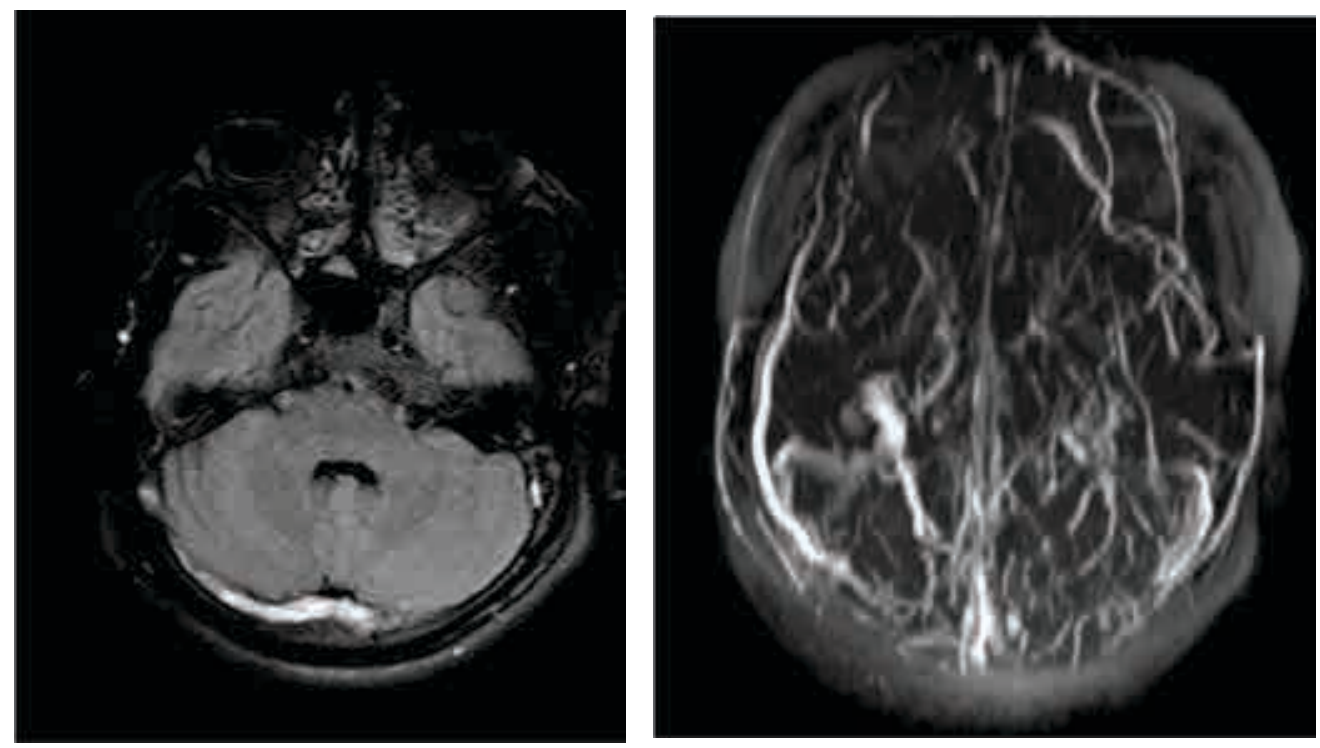

FIGURE $2(a, b):$ MRI FLAIR and venography images of one of the patient shows hyperintensity in right transverse sinus on FLAIR image and venogram showing thrombosis of superior sagittal sinus, bilateral transverse and sigmoid sinus. Also we see vein of labbe draining into right transverse sinus in fig 2(b). 
TABLE 1. Correlation of demography and type of presentation with outcome at discharge

\begin{tabular}{|c|c|c|c|c|}
\hline \multicolumn{2}{|l|}{ Variable } & $\begin{array}{l}\text { Poor outcome } \\
(n=16)\end{array}$ & $\begin{array}{l}\text { Good outcome } \\
(n=24)\end{array}$ & P value \\
\hline \multicolumn{2}{|c|}{ Age $\leq 30$ yrs $(n=20)$} & $6(15 \%)$ & $14(35 \%)$ & \multirow{2}{*}{$P$ value $=0.197$} \\
\hline \multicolumn{2}{|c|}{ Age $>30 y r s(n=20)$} & $10(25 \%)$ & $10(25 \%)$ & \\
\hline \multicolumn{2}{|c|}{ Males $(n=24)$} & $11(27.5 \%)$ & $13(32.5 \%)$ & \multirow{2}{*}{$P$ value $=0.356$} \\
\hline \multicolumn{2}{|c|}{ Females $(n=16)$} & $5(12.5 \%)$ & $11(27.5 \%)$ & \\
\hline \multicolumn{2}{|c|}{ Rural (n = 14) } & $3(7.5 \%)$ & $11(27.5 \%)$ & \multirow{2}{*}{$P$ value $=0.079$} \\
\hline \multicolumn{2}{|c|}{ Urban $(n=26)$} & $1332.5 \%)$ & $13(32.5 \%)$ & \\
\hline \multirow{3}{*}{$\begin{array}{l}\text { Type of } \\
\text { presenta }\end{array}$} & Headache $(n=16)$ & $2(5 \%)$ & $14(35 \%)$ & \multirow{3}{*}{$P$ value $=0.002^{\#}$} \\
\hline & Stroke $(n=13)$ & $10(25 \%)$ & $3(7.5 \%)$ & \\
\hline & Seizures $(n=11)$ & $4(10 \%)$ & $7(17.5 \%)$ & \\
\hline
\end{tabular}

\#-st ant

neurological deficits or stroke-like presentation $(\mathrm{n}=13)$ were mostly dependent with the poor outcome while the patients who presented with headache alone $(n=16)$ and seizures $(n=11)$ were mostly independent with good outcome (Table 1).

The study revealed that the patients with good outcome had longer mean pre-hospitalization period and shorter hospital stay as compared to patients with poor outcome ( $\mathrm{p}<0.056$ at $94.4 \%$ CI and $<0.065$ at $93.5 \% \mathrm{CI}$ respectively). The average GCS score at admission and discharge in the good outcome group was significantly higher as compared to poor outcome $(\mathrm{p}<0.002$ and $\mathrm{p}<0.008$ respectively) (Table 2 ).

The relationship between radiological parameters and outcome is shown in Table 3. On comparing radiological profile, individually none of the radiological parameter showed statically significant difference among two subgroups ( $p>0.05)$, except for the correlation of unilateral parenchymal lesion $>30 \mathrm{ml}(\mathrm{p}<0.001)$ with poor outcome. On comparing the outcome as per the number of sinuses involved, there was no significant difference in outcome in patients with single or multiple sinuses involvements $(\mathrm{p}>0.05)$.

The radiological characteristics of the patient were studied under three types of radiological presentations 1) Those without any parenchymal lesions 2) parenchymal lesion without mass effect 3) parenchymal lesion with mass effect. In our study group $(n=40)$, there were $n=15$ patients without any parenchymal lesion, $\mathrm{n}=12$ patients with parenchymal lesions without mass effect and $\mathrm{n}=13$ patients with parenchymal lesions with mass effect.

Among the subgroups, $n=11(84.62 \%)$ out of 13 patients with parenchymal lesion with mass effect were dependent/dead and had poor outcome at

TABLE 2. Comparison of pre-hospitalization period, GCS at admission, hospital stay, GCS at discharge and BMI with clinical outcomes

\begin{tabular}{|c|c|c|c|c|c|c|}
\hline \multirow{2}{*}{ Parameter } & \multirow{2}{*}{$\begin{array}{l}\text { Clinical } \\
\text { Outcome }\end{array}$} & \multirow{2}{*}{$\begin{array}{c}\text { Scatter } \\
\text { Mean } \pm \text { SD }\end{array}$} & \multicolumn{2}{|c|}{$95.0 \% \mathrm{Cl}$ for Mean } & \multirow{2}{*}{ t-statistic } & \multirow{2}{*}{$\begin{array}{l}\text { p-value } \\
\text { (LOS) }\end{array}$} \\
\hline & & & LB & UB & & \\
\hline \multirow{2}{*}{$\begin{array}{l}\text { Pre-hospitalization } \\
\text { period (day) }\end{array}$} & Poor & $5.81 \pm 3.45$ & 3.97 & 7.65 & \multirow{2}{*}{1.98} & \multirow{2}{*}{$p<0.056$} \\
\hline & Good & $13.25 \pm 14.74$ & 7.03 & 19.47 & & \\
\hline \multirow{2}{*}{ GCS Score at admission } & Poor & $12.31 \pm 3.30$ & 10.55 & 14.07 & \multirow{2}{*}{3.26} & \multirow{2}{*}{$p<0.002^{\#}$} \\
\hline & Good & $14.63 \pm 0.92$ & 14.23 & 15.02 & & \\
\hline \multirow{2}{*}{$\begin{array}{l}\text { Homocysteine } \\
(\mu \mathrm{mol} / \mathrm{l})\end{array}$} & Poor & $23.86 \pm 21.49$ & 12.41 & 35.31 & \multirow{2}{*}{0.31} & \multirow{2}{*}{$p>0.05^{\otimes}$} \\
\hline & Good & $26.01 \pm 21.20$ & 17.05 & 34.96 & & \\
\hline \multirow{2}{*}{$\begin{array}{l}\text { Hospital stay } \\
\text { (day) }\end{array}$} & Poor & $11.50 \pm 10.78$ & 5.75 & 17.25 & \multirow{2}{*}{1.90} & \multirow{2}{*}{$p<0.065^{\wedge}$} \\
\hline & Good & $7.25 \pm 1.82$ & 6.48 & 8.02 & & \\
\hline \multirow{2}{*}{ GCS score at discharge } & Poor & $12.38 \pm 4.65$ & 9.90 & 14.85 & \multirow{2}{*}{2.79} & \multirow{2}{*}{$p<0.008^{\#}$} \\
\hline & Good & $15.00 \pm 0.00$ & 15.00 & 15.00 & & \\
\hline \multirow{2}{*}{$\begin{array}{l}\text { Body mass index } \\
\left(\mathrm{kg} / \mathrm{m}^{2}\right)\end{array}$} & Poor & $24.02 \pm 3.82$ & 21.98 & 26.05 & \multirow{2}{*}{0.94} & \multirow{2}{*}{$p>0.05^{\otimes}$} \\
\hline & Good & $22.76 \pm 4.33$ & 20.93 & 24.59 & & \\
\hline
\end{tabular}


TABLE 3. Relationship between radiological characteristics with outcome

\begin{tabular}{|c|c|c|c|c|c|}
\hline \multirow{2}{*}{\multicolumn{2}{|c|}{ Radiological characteristics }} & \multicolumn{2}{|c|}{ Clinical outcome } & \multirow{3}{*}{$\begin{array}{c}\text { Total } \\
27 \\
67.5 \%\end{array}$} & \multirow{3}{*}{$\begin{array}{c}\text { p-value (LOS) } \\
\chi_{1}^{2}=0.02^{\otimes} p>0.05\end{array}$} \\
\hline & & \multirow{2}{*}{$\begin{array}{c}\text { Good } \\
16 \\
40.0 \% \\
\end{array}$} & \multirow{2}{*}{$\begin{array}{c}\text { Poor } \\
11 \\
27.5 \% \\
\end{array}$} & & \\
\hline $\begin{array}{l}\text { Superior } \pm \text { Inferior sagittal } \\
\text { sinus }\end{array}$ & Present & & & & \\
\hline Straight sinus & Present & $\begin{array}{c}5 \\
12.5 \% \\
\end{array}$ & $\begin{array}{c}4 \\
10.0 \% \\
\end{array}$ & $\begin{array}{c}9 \\
22.5 \% \\
\end{array}$ & $\chi_{1}^{2}=0.10^{\otimes} p>0.05$ \\
\hline Right transverse sinus & Present & $\begin{array}{c}12 \\
30.0 \% \\
\end{array}$ & $\begin{array}{c}6 \\
15.0 \% \\
\end{array}$ & $\begin{array}{c}18 \\
45.0 \% \\
\end{array}$ & $\chi_{1}^{2}=0.61^{\otimes} p>0.05$ \\
\hline Left transverse sinus & Present & $\begin{array}{c}11 \\
27.5 \% \\
\end{array}$ & $\begin{array}{c}9 \\
22.5 \% \\
\end{array}$ & $\begin{array}{c}20 \\
50.0 \% \\
\end{array}$ & $\chi_{1}^{2}=0.42^{\otimes} p>0.05$ \\
\hline $\begin{array}{l}\text { Right sigmoid sinus } \pm \text { Internal } \\
\text { jugular vein }\end{array}$ & Present & $\begin{array}{c}13 \\
32.5 \% \\
\end{array}$ & $\begin{array}{c}6 \\
15.0 \% \\
\end{array}$ & $\begin{array}{c}19 \\
47.5 \% \\
\end{array}$ & $\chi_{1}^{2}=1.07^{\otimes} p>0.05$ \\
\hline $\begin{array}{l}\text { Left sigmoid sinus } \pm \text { Internal } \\
\text { jugular vein }\end{array}$ & Present & $\begin{array}{c}9 \\
22.5 \% \\
\end{array}$ & $\begin{array}{c}7 \\
17.5 \% \\
\end{array}$ & $\begin{array}{c}16 \\
40.0 \% \\
\end{array}$ & $\chi_{1}^{2}=0.16^{\otimes} p>0.05$ \\
\hline Cortical veins & Present & $\begin{array}{c}5 \\
12.5 \%\end{array}$ & $\begin{array}{c}6 \\
15.0 \%\end{array}$ & $\begin{array}{c}11 \\
27.5 \%\end{array}$ & $\chi_{1}^{2}=1.34^{\otimes} p>0.05$ \\
\hline $\mathrm{U} / \mathrm{L}$ Lesion $\leq \mathbf{3 0} \mathrm{ml}$ & Present & $\begin{array}{c}6 \\
15.0 \%\end{array}$ & $\begin{array}{c}5 \\
12.5 \%\end{array}$ & $\begin{array}{c}11 \\
27.5 \%\end{array}$ & $\chi_{1}^{2}=0.19^{\otimes} p>0.05$ \\
\hline $\mathrm{B} / \mathrm{L}$ Lesion $\leq \mathbf{3 0} \mathrm{ml}$ & Present & $\begin{array}{c}1 \\
2.5 \% \\
\end{array}$ & $\begin{array}{c}2 \\
5.0 \% \\
\end{array}$ & $\begin{array}{c}3 \\
7.5 \% \\
\end{array}$ & $\chi_{1}^{2}=0.96^{\otimes} p>0.05$ \\
\hline $\mathrm{U} / \mathrm{L}$ Lesion $>30 \mathrm{ml}$ & Present & $\begin{array}{c}2 \\
5.0 \% \\
\end{array}$ & $\begin{array}{c}9 \\
22.5 \% \\
\end{array}$ & $\begin{array}{c}11 \\
27.5 \% \\
\end{array}$ & $\chi_{1}^{2}=11.06^{\#} p<0.001^{*}$ \\
\hline $\mathrm{B} / \mathrm{L}$ Lesion $>30 \mathrm{ml}$ & Present & $\begin{array}{c}0 \\
0.0 \%\end{array}$ & $\begin{array}{c}0 \\
0.0 \%\end{array}$ & $\begin{array}{c}0 \\
0.0 \%\end{array}$ & $N A$ \\
\hline
\end{tabular}

discharge, $\mathrm{n}=5(41.67 \%)$ out of 12 patients with parenchymal lesions without mass effect had poor outcome and none of the patient $(0 \%)$ without parenchymal lesion group had poor outcome at discharge. While studying the late outcome at one year, in the parenchymal lesion with mass effect group, $\mathrm{n}=6(46.15 \%)$ patients were dependent/ dead with poor outcome, none of the patients was dependent/dead in the group with parenchymal lesion without mass effect and only single $n=1$ (6.6\%) patient was dependant with poor outcome in parenchymal lesion group (Table 4).

Logistic regression model for prediction of poor outcome of cerebral venous thrombosis at discharge showed that the presence of headache $(p<0.05)$ with lower GCS score at admission $(p<0.05)$ found to be the significant predictors of the poor outcome of cerebral venous thrombosis whereas the seizure $(\mathrm{p}>0.05)$ with lower GCS score $(p>0.05)$ were the insignificant predictors of the poor outcome of cerebral venous thrombosis at discharge.

Logistic regression model for prediction of the late outcome at one year showed that lower GCS score at discharge $(\mathrm{p}<0.03)$ found to be the significant predictor while lower GCS score at admission $(\mathrm{p}<0.09)$ found to be the poorly significant (at $91.0 \% \mathrm{CI}$ ) predictor of the poor outcome of cerebral venous thrombosis at one year (Table 5).

At discharge, the probability of correct prediction of logistic model found to be $82.5 \%$. However, the sensitivity of the prediction (poor outcome) found to be $68.8 \%$ at discharge as compared to specificity of prediction (good outcome) was $91.7 \%$.

TABLE 4. Radiological groups and clinical outcome

\begin{tabular}{|l|c|c|c|c|}
\hline \multirow{2}{*}{ Group } & \multicolumn{2}{|c|}{ Outcome at discharge } & \multicolumn{2}{c|}{ Outcome at 1 year } \\
\cline { 2 - 5 } & $\begin{array}{c}\text { Dependant/Poor } \\
(\mathbf{n}=\mathbf{1 6})\end{array}$ & $\begin{array}{c}\text { Independent/ Good } \\
(\mathbf{n}=\mathbf{2 4})\end{array}$ & $\begin{array}{c}\text { Dependant/Poor } \\
(\mathbf{n}=\mathbf{7})\end{array}$ & $\begin{array}{c}\text { Independent/Good } \\
(\mathbf{n}=\mathbf{3 3})\end{array}$ \\
\hline $\begin{array}{l}\text { No parenchymal lesion } \\
(\mathbf{n}=\mathbf{1 5})\end{array}$ & $0(0 \%)$ & $15(100 \%)$ & $1(6.65)$ & $14(93.33 \%)$ \\
\hline $\begin{array}{l}\text { Parenchymal lesion } \\
\text { without mass effect ( } \\
=\mathbf{1 2})\end{array}$ & $5(41.67 \%)$ & $7(58.33 \%)$ & $0(0 \%)$ & $12(100 \%)$ \\
\hline $\begin{array}{l}\text { Parenchymal lesion with } \\
\text { mass effect (n= 13) }\end{array}$ & $11(84.62 \%)$ & $2(15.38 \%)$ & $6(46.15 \%)$ & $7(53.85 \%)$ \\
\hline
\end{tabular}


TABLE 5. Predictors of poor outcome of CVT at discharge and one year

\begin{tabular}{|c|c|c|c|c|c|}
\hline \multirow{2}{*}{ Independent predictors } & \multirow{2}{*}{$\beta$} & \multirow{2}{*}{$\begin{array}{c}\text { p-value } \\
\text { (LOS) }\end{array}$} & \multirow{2}{*}{$\begin{array}{l}\text { Adjusted } \\
\text { Odds Ratio }\end{array}$} & \multicolumn{2}{|c|}{$95 \% \mathrm{Cl}$ of $\mathrm{AOR}$} \\
\hline & & & & Upper & Lower \\
\hline \multicolumn{6}{|l|}{ At discharge } \\
\hline Headache (Yes) & -2.639 & $p<0.05^{*}$ & 0.07 & 0.01 & 0.83 \\
\hline Seizure (Yes) & -2.264 & $p>0.05^{\otimes}$ & 0.10 & 0.01 & 1.80 \\
\hline GCS score at admission & -0.881 & $p<0.05 *$ & 0.41 & 0.17 & 0.99 \\
\hline GCS score at discharge & -5.155 & $\mathrm{p}>0.05^{\otimes}$ & 0.01 & 0.00 & - \\
\hline \multicolumn{6}{|l|}{ At one year } \\
\hline Headache (Yes) & 0.012 & $\mathrm{p}>0.05^{\otimes}$ & 1.01 & 0.03 & 40.48 \\
\hline Seizure (Yes) & -0.442 & $\mathrm{p}>0.05^{\otimes}$ & 0.64 & 0.02 & 23.97 \\
\hline GCS score at admission & -1.031 & $\mathrm{p}<0.09^{\wedge}$ & 0.36 & 0.11 & 1.15 \\
\hline GCS score at discharge & -0.576 & $\mathrm{p}<0.03^{*}$ & 0.56 & 0.34 & 0.94 \\
\hline \multicolumn{6}{|c|}{${ }^{*}$ The test variable is ant at the 0.000 levels of } \\
\hline $\begin{array}{r}\text { ant at the } 0.05 \text { I } \\
\text { ance. [LOS - I }\end{array}$ & lof & $\begin{array}{l}\text { ance. } \wedge \text { The } \\
\text { ance; Std. E }\end{array}$ & $\begin{array}{l}\text { variable is } p \\
\text { - standard }\end{array}$ & $\begin{array}{l}y \\
r ; \mathrm{Cl}-\mathrm{c}\end{array}$ & $\begin{array}{c}\text { at the } 0.0 \mathrm{~s} \\
\text { nce inter }\end{array}$ \\
\hline
\end{tabular}

The parenchymal lesion with mass effect among CVT patients at discharge and one year observed as the most significant $(\mathrm{p}<0.0001)$ predictor with a cutoff score of $\mathrm{mRS}$ of $\geq 3$ points whereas no parenchymal lesion observed as the most significant $(p<0.0001)$ predictor with a cutoff score of mRS of $<3$ points (Table 6 ).

AUC shows that diagnostic accuracy of test variable, parenchymal lesion with mass effect predicted scores of $\mathrm{mRS}$ at discharge had indicated that the specific sensitivity of predicting $\mathrm{mRS}$ score (cutoff: $\geq 3$ ) was $61.54 \%$ with specificity of $85.19 \%$ while the NPV $(82.10 \%)$ was greater than PPV $(66.70 \%)$. But, the specific sensitivity of test variable, absence of parenchymal lesion of predicting mRS score (cutoff: <3) found to be $100.0 \%$ with specificity of $48.00 \%$ while the NPV $(100.0 \%)$ was greater than PPV (53.60\%) at discharge.

Diagnostic accuracy of test variable, parenchymal lesion with mass effect predicted scores of
$\mathrm{mRS}$ at one year had indicated that the specific sensitivity of predicting mRS score (cutoff: $\geq 3$ ) was $38.46 \%$ with specificity of $100.00 \%$ while the NPV (77.10\%) was smaller than PPV (100.0\%). The specific sensitivity of test variable, absence of parenchymal lesion of predicting mRS score (cutoff $<3$ ) found to be $100.0 \%$ with specificity of $20.00 \%$ at one year (Figure 3,4 ).

\section{DISCUSSION}

Cerebral venous thrombosis (CVT) is a less common cause of stroke with a varying range of clinical presentations, predisposing factors, radiological features, and outcomes. In an autopsy series in the late $1980 \mathrm{~s}$, Banerjee et al. found that CVT accounted for almost $10 \%$ of all strokes in India [9]. It was reported as the commonest cause of stroke in young women in India [10]. Our results showed a higher prevalence of CVT in the

TABLE 6. Area under curve (AUC) of $m R S$ score at discharge and one year and diagnostic performances of test variables

\begin{tabular}{|c|c|c|c|c|c|c|}
\hline \multicolumn{3}{|c|}{ Predictor of poor outcome of CVT (test variables) } & \multirow[t]{2}{*}{ AUC } & \multirow[t]{2}{*}{ p-value } & \multicolumn{2}{|c|}{$\begin{array}{c}\text { 95\% Confidence Interval of } \\
\text { AUC }\end{array}$} \\
\hline & & & & & LB & \multirow{2}{*}{$\frac{\text { UB }}{0.954}$} \\
\hline \multirow{6}{*}{ 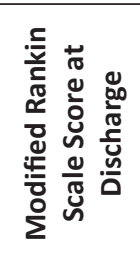 } & \multicolumn{2}{|c|}{ Parenchymal lesion with mass effect } & 0.868 & $<0.0001^{\#}$ & 0.723 & \\
\hline & \multicolumn{2}{|c|}{ No parenchymal lesion } & 0.816 & $<0.0001^{\#}$ & 0.662 & 0.921 \\
\hline & \multicolumn{6}{|c|}{ Diagnostic performances of test variables } \\
\hline & Cut-off point & \multicolumn{2}{|c|}{ Sensitivity } & Specificity & PPV & NPV \\
\hline & >3 points & \multicolumn{2}{|l|}{$61.54 \%$} & $85.19 \%$ & $66.70 \%$ & $82.10 \%$ \\
\hline & $\leq 3$ points & $100.0 \%$ & \multicolumn{2}{|c|}{$48.00 \%$} & $53.6 \%$ & $100.0 \%$ \\
\hline
\end{tabular}




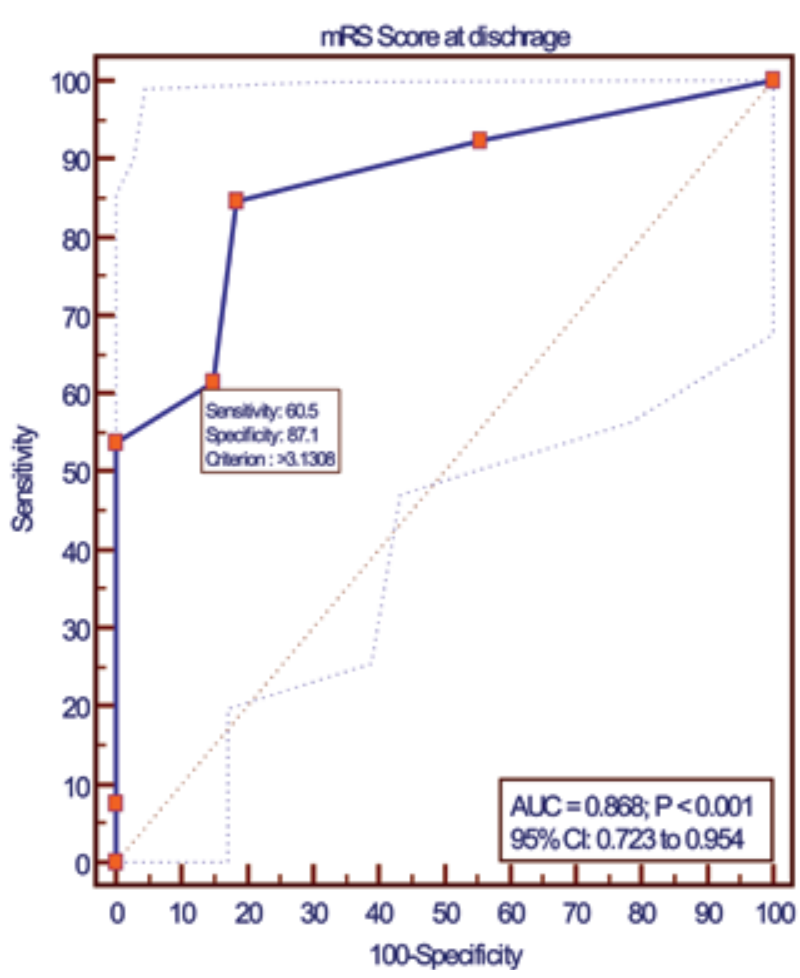

FIGURE 3. ROC curve shows the relationship between sensitivity and specificity of score of $m R S$ at discharge for possible cut-offs to differentiate between CVT patients with and without parenchymal lesion with mass effect.

male group (60\%) compared to females (40\%). These results are in concordance with the recent studies where CVT was found more commonly in males up to $54 \%$. [1,8]. A series of $110 \mathrm{CVT}$ patients in a study conducted by Parikh et al. had a male dominance [11]. Male predominance may be due to the rising consumption of alcohol by men and improved obstetrics care in our country.

In the largest hospital-based prospective cohort study from India (Nizam's Institute Venous Stroke Registry [NIVSR]) by Narayan et al. the mean age of the patients was 31.3 years [8]. In our study the mean age of patients was 32.45 yrs which is comparable to earlier studies $[1,12]$.

The mean hospital stay in our study was 8.95 days which was shorter than the average duration of hospital stay (16.1 days) in Nizam's study [8]. The median hospital stay was found to be around 17 days in the ISCVT study [13].

CVT was found to be associated with multiple risk factors studied in literature including genetic or acquired thrombophilia, malignancy, infection, and autoimmune disorders $[14,15]$. Hyperhomocysteinemia (18.4\%) and anemia (18.2\%) were reported as the most common risk factors by

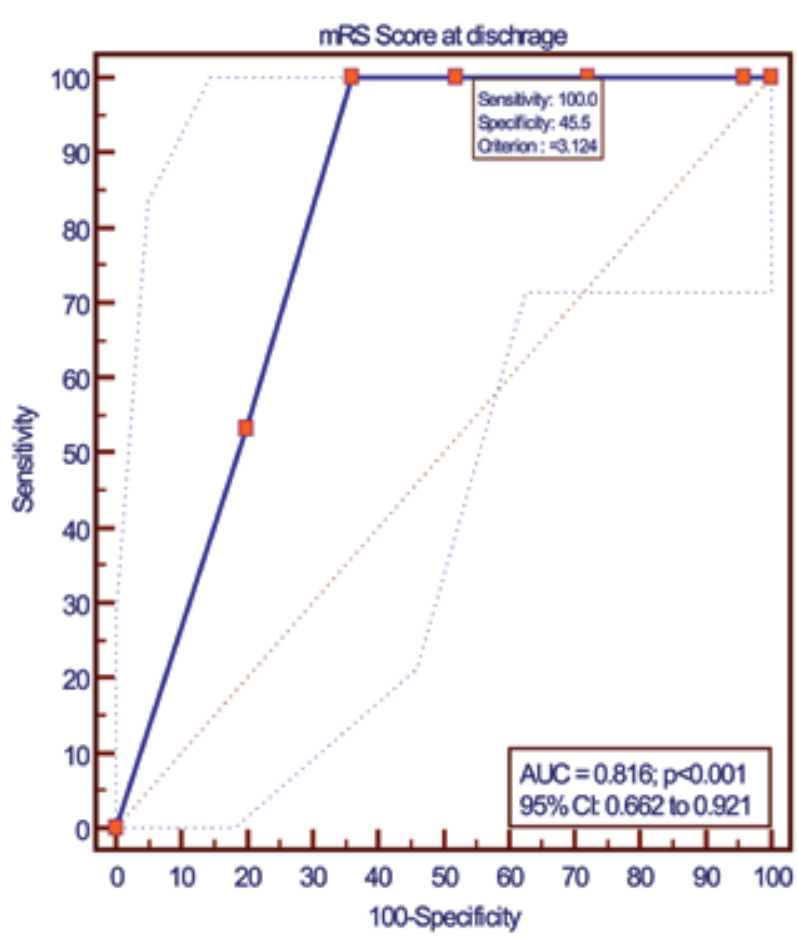

FIGURE 4. ROC curve shows the relationship between sensitivity and specificity of score of $m R S$ at discharge for possible cut-offs to differentiate between CVT patients with no parenchymal lesion and parenchymal lesion

Narayan et al. in their study [8]. In our study, hyperhomocysteinemia was the most common risk factor in 55\% patients. Among the acquired causes, alcohol (22.5\%) and pregnancy/post-partum $(17.5 \%)$ state were the most common risk factors.

Clinical findings in CVT fall into two major categories: Those related to increased intracranial pressure due to impaired venous drainage and, those related to focal brain injury from venous ischemia/ infarction or hemorrhage [16]. Focal neurological deficit may occur depending on the area involved. In the NIVSR cohort, a stroke-like presentation was present in $28.5 \%$ of patients, isolated seizures in $29.4 \%$, benign intracranial hypertension like presentation in $18.2 \%$, encephalopathy in $25.2 \%$, and psychosis was observed in $1.8 \%$ patients [8]. In our cohort most the common presentation of CVT was stroke in $40 \%$ of patients, followed by secondary headache with raised intracranial pressure in $37.5 \%$ patients, and $22.5 \%$ patients presented with seizures.

The type of presentation was found to have a strong correlation with the outcome. Those patients presenting with focal neurological deficits or stroke-like presentation were commonly found to 
have dependent/death/poor outcome while patients presenting with secondary headache and seizures had a prediction for independent/good outcome. This was in concordance with previous studies where presentation with headache or isolated intracranial hypertension had a good outcome [13] and presentation with focal neurological deficits/ stroke-like presentation was associated with poor outcome [8]. In ISCVT study involving 624 patients of CVT, Ferro et al. found $57.1 \%$ patients had no residual symptom or signs (mRS-0), 22\% had minor residual symptoms (mRS-1), 7.5\% had mild impairments (mRS-2), 2.9\% were moderately impaired (mRS-3), 2.2\% were severely handicapped (mRS-4 or 5), and $8.3 \%$ had died at the end of follow up [13].

Our study found that the longer pre-hospitalization period is correlated with good outcome. The higher GCS score at admission and discharge was also significantly related to good outcome. Similar results were obtained in Nizam's study and higher GCS was found to be associated with good outcome and low GCS was a predicting factor of poor outcome [8].

Superior sagittal sinus with or without inferior sagittal sinus was the most frequently $(67.5 \%)$ involved sinus in our study. This was similar to results of previous studies where Superior sagittal sinus was involved in $68 \%$ of cases [8]. In a recent study, transverse sinus was the most frequently involved sinus in $67 \%$ of patients [1]. Khosya et al in his study of $71 \mathrm{CVT}$ patients found superior sagittal sinus to be the most frequently thrombosed in up to $53.84 \%$ of patients [17]. While the individual sinuses involved and the number of sinuses whether single or multiple did not show any relationship to the patient's clinical outcome. In our study, cortical veins thrombosis was found to be associated with poor outcome although it was not found to be in a statistically significant range. Some studies have found it to be an important risk factor for poor outcome $[1,8]$.

Unilateral large parenchymal lesions $(>30 \mathrm{ml})$ were found to be associated with poor outcome in our study and the association was found to be statistically very significant. Various radiological scores including clinical, MRI, and MRV have been developed to predict death and disability of
CVST [18,19]. Barboza et al. described a CVT-grading scale including gender, level of consciousness, bilateral Babinski's sign, parenchymal lesion, and intracerebral hemorrhage, which have an accuracy of $91.6 \%$ for the prediction of 30-day mortality and $85.3 \%$ for $\mathrm{mRS}>2$ [20].

By studying the radiological parameters with this perspective we found very interesting and informative results. It showed that the presentation of CVT as parenchymal lesion with mass effect is a predictor of dependant/death/poor clinical outcome at discharge and after one year (late outcome). While patients without parenchymal lesions and those with parenchymal lesion without mass effect have prediction for Independent/good clinical outcome at discharge and after 1 year. One of the studies by Girot M et al. correlated parenchymal lesion with clinical outcome, found poor outcome among the CVT patients with parenchymal hemorrhage [21].

Few limitations of our study were the small sample size which might explain we did not get significant results of the effect of duration of hospital stay and single or multiple sinuses on clinical outcome and thrombophilia profile could not be done for all patients due to financial constraints.

\section{CONCLUSIONS}

To conclude, our prospective observational study results showed longer pre-hospitalization period, higher GCS score at admission and discharge, presentation with headache, and radiological parameters like absence of parenchymal lesion and parenchymal lesion without mass effect were the predictors of good/independent clinical outcome(early and late). While stroke-like presentation or with focal deficits, unilateral large parenchymal lesions $>30 \mathrm{ml}$, low GCS at admission and discharge, presentation of headache with lower GCS and parenchymal lesion with mass effect are the strong predictors of dependant/death/poor clinical outcome (early and late).

Other factors of urban/rural background, body mass index, homocysteine level, duration of hospital stay, respective sinuses involved, single or multiple sinus thrombosis and site of parenchymal lesion showed no direct correlation with the outcome. 


\section{REFERENCES}

1. Kalita J, Singh VK, Jain N, Misra UK, Kumar S. Cerebral Venous Sinus Thrombosis Score and its Correlation with Clinical and MRI Findings. J Stroke Cerebrovasc Dis. 2019;28(11):104324.

2. Kimber. J. Cerebral venous sinus thrombosis. QJMed. 2002; 95:137-142.

3. Bousser MG, Chiras J, Bories J, Castaigne P. Cerebral venous thrombosis - a review of 38 cases. Stroke. 1985;16:199-213.

4. Nagaraja D, Taly AB, Sarala Das: Puerperal cerebral venous thrombosis. In: Progress in Clinical Neurosciences, Sinha KK, Chandra P (Eds) NSI Publication, Ranchi 1989;325-338.

5. Kalita J, Bandal V, Misra UK, Phadke RV. Cerebral venous sinus thrombosis in a tertiary care setting in India. QJM 2006;99:491-2.

6. Bergui M, Bradac GB, Daniele D. Brain lesions due to cerebral venous thrombosis do not correlate with sinus involvement. Neuroradiology 1999;41:419-424.

7. Zubkov AY, McBane RD, Brown RD, Rabinstein AA. Brain lesions in cerebral venous sinus thrombosis. Stroke. 2009;40:1509-1511.

8. Narayan D, Kaul S, Ravishankar K, Suryaprabha T, Bandaru VC, Mridula KR, et al. Risk factors, clinical profile, and long-term outcome of 428 patients of cerebral sinus venous thrombosis: Insights from Nizam's Institute Venous Stroke Registry, Hyderabad (India). Neurol India. 2012;60:154-9.

9. Banerjee AK, Varma M, Vasista RK, Chopra JS. Cerebrovascular disease in north-west India: A study of necropsy material. J Neurol Neurosurg Psychiatry. 1989;52:512-5.

10. Bansal BC, Gupta RR, Prakash C. Stroke during pregnancy and puerperium in young females below the age of 40 years as a result of cerebral venous/venous sinus thrombosis. Jpn Heart J. 1980;21:171-73.

11. Parikh PM, Sukthankar RU, Parikh A, Pipalia DH, Sidhva SJ, Ramakanten R, et al. Cerebral venous thrombosis. J Assoc Physicians India. 1987;35:349-51.
12. Pai N, Ghosh K, Shetty S. Hereditary thrombophilia in cerebral venous thrombosis: A study from India. Blood Coagul Fibrinolysis. 2013;24:540-3.

13. Ferro JM, Canhao P, Stam J, Bousser MG, Barinagarrementeria F. Prognosis of cerebral vein and dural sinus thrombosis: results of the International Study on Cerebral Vein and Dural Sinus Thrombosis (ISCVT). Stroke. 2004;35:664-670.

14. Weih M, Vetter B, Castell S, Ziemer S, Kulozik AE, Einhaupl KM. Hereditary thrombophilia in cerebral venous thrombosis. Cerebrovasc Dis. 2000;10:161-162.

15. Haghighi AB, Edgell RC, Cruz-Flores S, Feen E, Piriyawat $P$, Vora $\mathrm{N}$, et al. Mortality of cerebral venous-sinus thrombosis in a large national sample. Stroke. 2012;43:262-264.

16. Dash D, Prasad K, Joseph L. Cerebral venous thrombosis: An Indian perspective. Neurol India. 2015;63:318-328.

17. Khosya S. A Study of Clinical Profile, Risk Factors and Outcome of the Cerebral Venous Sinus Thrombosis (CVST): An Experience at a Tertiary Care Center, India. Austin J Neurol Disord Epilepsy. 2018;5(2):1041.

18. Ferro JM, Bacelar-Nicolau H, Rodrigues $\mathrm{T}$, et al. Risk score to predict the outcome of patients with cerebral vein and dural sinus thrombosis. Cerebrovasc Dis. 2009;28:39-44.

19. Koopman K, Uyttenboogaart M, Vroomen PC, et al. Development and validation of a predictive outcome score of cerebral venous thrombosis. J Neurol Sci. 2009;276:66-68.

20. Barboza MA, Chiquete E, Arauz A, et al. A practical score for prediction of outcome after cerebral venous thrombosis. Front Neurol. 2018;9:882.

21. Girot M, Ferro JM, Canhao P, et al. Predictors of outcome in patients with cerebral venous thrombosis and intracerebral hemorrhage. Stroke. 2007;38(2):337-342. 